\title{
Synthesis and characterization of Gd-doped magnetite nanoparticles
}

Honghu Zhang ${ }^{\text {a,b }}$, Vikash Malik ${ }^{\mathrm{a}}$, Surya Mallapragada, ${ }^{\mathrm{a}, \mathrm{c}}$, Mufit Akinc ${ }^{\mathrm{a}, \mathrm{b}, *}$

${ }^{\text {a }}$ Ames Laboratory, U.S. Department of Energy, Ames, Iowa 50011, USA

${ }^{\mathrm{b}}$ Department of Materials Science \& Engineering, Iowa State University, Ames, Iowa 50011, USA

${ }^{\mathrm{c}}$ Department of Chemical \& Biological Engineering, Iowa State University, Ames, Iowa 50011, USA

*Corresponding Author: Tel.: +1-515-294-0738; fax: +1-515-294-5444

E-mail address: $\underline{\text { makinc@ @iastate.edu }}$

(C) 2016. This manuscript version is made available under the Elsevier user license http://www.elsevier.com/open-access/userlicense/1.0/ 


\begin{abstract}
Synthesis of magnetite nanoparticles has attracted increasing interest due to their importance in biomedical and technological applications. Tunable magnetic properties of magnetite nanoparticles to meet specific requirements will greatly expand the spectrum of applications. Tremendous efforts have been devoted to studying and controlling the size, shape and magnetic properties of magnetite nanoparticles. Here we investigate gadolinium $(\mathrm{Gd})$ doping to influence the growth process as well as magnetic properties of magnetite nanocrystals via a simple co-precipitation method under mild conditions in aqueous media. Gd doping was found to affect the growth process leading to synthesis of controllable particle sizes under the conditions tested $\left(0-10\right.$ at. $\left.\% \mathrm{Gd}^{3+}\right)$. Typically, undoped and 5 at. $\%$ Gd-doped magnetite nanoparticles were found to have crystal sizes of about 18 and $44 \mathrm{~nm}$, respectively, supported by X-ray diffraction and transmission electron microscopy. Our results showed that Gd-doped nanoparticles retained the magnetite crystal structure, with $\mathrm{Gd}^{3+}$ randomly incorporated in the crystal lattice, probably in the octahedral sites. The composition of 5 at.\% Gd-doped magnetite was $\mathrm{Fe}_{(3-\mathrm{x})} \mathrm{Gd}_{\mathrm{x}} \mathrm{O}_{4}(\mathrm{x}=0.085 \pm 0.002)$, as determined by inductively coupled plasma-mass spectrometry. Gd-doped nanoparticles exhibited ferrimagnetic properties with small coercivity ( $\sim 65 \mathrm{Oe}$ ) and slightly decreased magnetization at $260 \mathrm{~K}$ in contrast to the undoped, superparamagnetic magnetite nanoparticles. Templation by the bacterial biomineralization protein Mmm6 did not appear to affect the growth of the Gd-doped magnetite particles synthesized by this method.
\end{abstract}

\title{
Keywords
}

Magnetite nanoparticles, Aqueous synthesis, Rare earth, Doping, Crystal size 


\section{Introduction}

In the past few decades, magnetic nanoparticles have attracted increasing research interest, not only for their fundamental science but also for their biological and technological applications [1, 2]. Especially, magnetite $\left(\mathrm{Fe}_{3} \mathrm{O}_{4}\right)$ - a magnetic iron oxide widespread in almost all of the different compartments of the global system [3] — nanoparticles have been investigated for many applications, such as magnetic data storage, magnetic resonance imaging (MRI) contrast enhancement, hyperthermia, and targeted drug delivery $[4,5]$.

The magnetic behavior of magnetite nanoparticles greatly depends on their size, shape, purity and crystal structure, which determines their applications. For instance, the size of magnetic particles typically used in biomedicine needs to be in the nanoscale range, so that their dimensions are smaller than or comparable to those of a cell, virus, protein or gene [6]. However, the smallest sized nanoparticles are not necessarily the best because they are often associated with very small magnetic moments and very weak magnetic anisotropy, which dramatically increase difficulties in manipulating the particles for applications with an external magnetic field at ambient temperature [5]. Bulk magnetite is ferrimagnetic with a multiple domain structure, but when the size of magnetite nanoparticles is below a threshold size $\mathrm{d}_{0}(80-100 \mathrm{~nm})$, these particles can no longer support static domain walls, and thus they exhibit ferrimagntetism with a stable single domain [5, 7-9]. When the size decreases further to a critical point $d_{s}(20-30 \mathrm{~nm})$, the magnetite nanoparticles become superparamagnetic at room temperature, as their magnetic moments are thermally equilibrated [5, 7-9]. Applications in data recording and spintronics require magnetic nanoparticles with single domains, while medical use of ferrofluids usually needs superparamagnetic nanoparticles $[1,4,6,9$, 10]. Therefore, size-controlled synthesis of magnetite nanoparticles for a desired purpose will have a huge impact on the technological and biological industries.

Numerous synthetic routes for magnetite nanoparticles have been developed, such as thermal decomposition of organometallic precursors in high-boiling organic solvents $[1,2,4,11,12]$. Although some of these methods produce size-controlled magnetite nanoparticles [13-16], they generally require extreme reaction conditions, such as high temperatures and toxic reagents. The classical co-precipitation method industrially used is by elevating the $\mathrm{pH}$ of a stoichiometric mixture of $\mathrm{Fe}$ (II) and $\mathrm{Fe}$ (III) ions in 
aqueous solution at room temperature, which is inexpensive, high-yield and safe [1,2]. But this method typically produces small $(<20 \mathrm{~nm})$ superparamagnetic nanoparticles with little control over the size $[1,2]$. Studies with focus on the size control of magnetite nanoparticles via simple co-precipitation method under ambient conditions are still lacking $[17,18]$.

Chemical purity is another important factor affecting the properties of magnetite. Magnetite has an inverse cubic spinel structure (Space group: $F d-3 m$ ), in which $32 \mathrm{O}^{2-}$ ions form a face-centered cubic (FCC) unit cell containing eight formula units $\left(\mathrm{Fe}_{24} \mathrm{O}_{32}\right)$ with the stoichiometric cations $(\mathrm{Fe}(\mathrm{III}) / \mathrm{Fe}(\mathrm{II})=2)[3,19]$. Magnetite is frequently non-stoichiometric, in which case some other cations (such as $\mathrm{Al}, \mathrm{Mn}, \mathrm{Ni}, \mathrm{Cu}, \mathrm{Co}$, etc.) are substituted for $\mathrm{Fe}$ due to the flexibility of the oxygen framework [3, 19]. Impurity doping introduces preferred magnetic orientation and alters the magnetic properties [20, 21]. Meanwhile, impurity doping plays a crucial role in nucleation and growth of nanocrystals and is successfully used to modify the size of nanocrystals $[22,23]$. However, relatively little attention has been paid to the size control of magnetite nanoparticles by chemical doping [20, 21], especially in high-yield and industrially robust coprecipitation methods under mild conditions.

Doping is one of the effective routes to modulating magnetism in magnetite nanoparticles [20, 21, 24-27]. Doping magnetite with lanthanide ions has been reported [24-27], as lanthanides potentially offer unique optical and magnetic properties due to their partially occupied 4f electronic state [28]. Particularly, the gadolinium $(\mathrm{Gd})$ ion is interesting, since it has a large magnetic moment resulting in an excellent magnetic resonance imaging effect and is used as a common MRI contrast agent [29-31]. Several chemical synthetic routes for magnetite nanoparticles have been employed to obtain Gd-doped magnetite nanoparticles, including thermal decomposition of organometallic precursors [24], hydrothermal method $[25,26]$ and a precipitation method with elevated temperatures [27]. Some of these methods produce high-quality magnetite nanoparticles, but they usually require high-temperature treatment, toxic reactants, or complicated operations. In addition, very little work has been focused on the role of Gd doping in the crystal growth process.

In this work, we introduce Gd ions to the conventional simple co-precipitation method to synthesize Gddoped magnetite nanoparticles under ambient conditions in aqueous media, and investigate the effect of Gd 
doping on crystal size, structure and magnetic properties of magnetite nanoparticles. We also examine the ability of a biomineralization protein Mms6 from magnetotactic bacteria [32] to synthesize Gd-doped magnetite nanoparticles, as Mms6 was recently found to bind iron ions with high affinity [33-36] and promote growth of uniform magnetite nanocrystals using the co-precipitation process [37].

\section{Experimental}

\subsection{Chemicals and Materials}

Iron (III) chloride hexahydrate $\left(\mathrm{FeCl}_{3} \cdot 6 \mathrm{H}_{2} \mathrm{O}, \geq 98 \%\right)$, gadolinium chloride hexahydrate $\left(\mathrm{GdCl}_{3} \cdot 6 \mathrm{H}_{2} \mathrm{O}\right.$, 99.999\%), and iron (II) chloride tetrahydrate $\left(\mathrm{FeCl}_{2} \cdot 4 \mathrm{H}_{2} \mathrm{O}, 99.99 \%\right)$ were all purchased from SigmaAldrich, and sodium hydroxide $(\mathrm{NaOH}, \geq 98 \%)$, potassium chloride $(\mathrm{KCl}, \geq 99 \%)$, and tris base $(\geq 99.8 \%)$ were purchased from Fisher Scientific. All chemicals were used as received without further treatment. The mature form of Mms6 protein used in this study was expressed with an N-terminal poly-histidine tag (Histag) on its N-terminal end as reported earlier [33, 35, 37]. It consists of 99 amino acid residues with a molecular mass of $\sim 10 \mathrm{kDa}$.

\subsection{Synthesis of Gd-doped magnetite nanoparticles}

Gd-doped magnetite nanoparticles were synthesized in aqueous solutions via a co-precipitation method. All solutions were degassed and purged with nitrogen prior to use. In a typical synthesis procedure, a precursor was prepared in a $1.7 \mathrm{~mL}$ plastic vial. The vial was placed in an ice bath and charged with $100 \mu \mathrm{L}$ protein solution containing $20 \mu \mathrm{g}$ Mms6, $20 \mathrm{mM}$ Tris, and $100 \mathrm{mM} \mathrm{KCl} \mathrm{(pH} 7.5$ ), $100 \mu \mathrm{L}$ of $0.5 \mathrm{M} \mathrm{FeCl}_{3}$, and $100 \mu \mathrm{L}$ of $0.25 \mathrm{M} \mathrm{FeCl}_{2}$. For 5 at.\% Gd-doped magnetite synthesis $5 \mu \mathrm{L}$ of $\mathrm{FeCl}_{3}$ was replaced by $5 \mu \mathrm{L}$ of $0.5 \mathrm{M} \mathrm{GdCl}_{3}$. The precursor was purged with nitrogen, sealed with Parafilm ${ }^{\circledR}$ and incubated at room temperature for one hour. Meanwhile, $2.5 \mathrm{~mL}$ of $0.1 \mathrm{M} \mathrm{NaOH}$ solution was added to a $5 \mathrm{~mL}$ pear-bottom flask. The flask was then degassed and filled with nitrogen. After incubation, the precursor was added dropwise into the $\mathrm{NaOH}$ solution in the flask under constant nitrogen flow. Upon contact with the $\mathrm{NaOH}$ solution, the precursor drop formed a black precipitate. The precipitate was aged at room temperature in the sealed flask under nitrogen purge for 5 days. The precipitate was collected at the bottom of the flask with a magnet, and the supernatant was removed. The precipitate was washed with degassed water $(3 \times 5 \mathrm{~mL})$ three times prior to characterization. 


\subsection{Characterization}

Powder X-ray Diffraction (XRD): XRD analysis of the powders (on pre-cleaned microscope slides) was performed using a PANalytical X'Pert Pro diffraction system equipped X'pert Data collector. The diffractometer was operated at $45 \mathrm{kV}$ and $40 \mathrm{~mA}$. A cobalt $\mathrm{K} \alpha$ radiation source with a wavelength of $0.17903 \mathrm{~nm}$ was employed. The scan rate was $0.02^{\circ} / \mathrm{s}$ with a step size of $0.017^{\circ}$ over the $2 \theta$ range of $20-80^{\circ}$ at a $\theta-2 \theta$ step-scan mode. Data analysis was carried out using PANalytical X'Pert HighScore Plus software. Inductively Coupled Plasma-Mass Spectrometry (ICP-MS): ICP-MS analysis was carried out using a Bruker Aurora Elite inductively coupled plasma mass spectrometer. Magnetite samples were dissolved in $70 \%$ nitric acid and then diluted with 3\% nitric acid. Plasma conditions were optimized with a standard solution for maximum signals, $\mathrm{CeO}^{+} / \mathrm{Ce}^{+}$ratios less than $2 \%$, and $\mathrm{Ba}^{++} / \mathrm{Ba}^{+}$ratios less than or equal to $3 \%$.

X-ray Photoelectron Spectroscopy (XPS): XPS analysis was conducted using a PHI 5500 multi-technique system with the non-monochromated $\mathrm{Al} \mathrm{K \alpha}(h v=1486.6 \mathrm{eV})$ radiation source. The vacuum dried powder samples were mounted on a two-sided tape. Binding energy was calibrated with the adventitious $\mathrm{C} 1 s\left(\mathrm{E}_{\mathrm{b}}=\right.$ $284.8 \mathrm{eV})$.

Transmission Electron Microscopy (TEM): Magnetite nanoparticles were imaged with an FEI Tecnai $\mathrm{G}^{2}$ F20 Scanning Transmission Electron Microscope operating at $200 \mathrm{kV}$. Diluted nanoparticle suspensions were placed on holey carbon-coated copper grids and dried in air at room temperature. Multiple areas of each sample were randomly chosen and examined.

Magnetization Measurements: Magnetic properties of the nanoparticles samples were measured using a 5T Quantum Design Magnetic Properties Measurement System (MPMS). A suspension of nanoparticles was tightly sealed in a gelatin capsule and all measurements were taken at or below $260 \mathrm{~K}$ at which solution is frozen in order to prevent particle movement during measurement. Magnetic hysteresis loop were measured at $5 \mathrm{~K}$ and $260 \mathrm{~K}$. 


\section{Results And Discussion}

\subsection{Crystal structure and chemical composition}

Structural analysis of the samples was carried out by XRD to assess the effect of Gd doping and the Mms6 protein on the structure of magnetite particles. In a typical study, 5 at.\% $\mathrm{Gd}^{3+}$ ions as fraction of trivalent

ions $\left(\left[\mathrm{Gd}^{3+}\right] /\left(\left[\mathrm{Fe}^{3+}\right]+\left[\mathrm{Gd}^{3+}\right]\right) \times 100 \%\right)$ were used to replace $\mathrm{Fe}^{3+}$ ions in magnetite. X-ray diffraction patterns showed that all the displayed peak line positions and relative intensities of undoped and 5 at. $\% \mathrm{Gd}-$ doped nanocrystals, with or without Mms6 biomineralization protein, were consistent with inverse cubic spinel structure of magnetite (JCPDS\# 19-0629).

In general, based on the XRD patterns alone, it is not easy to distinguish magnetite from maghemite $(\gamma$ $\mathrm{Fe}_{2} \mathrm{O}_{3}$ ), since magnetite can be transformed into maghemite by oxidation [1] and maghemite possesses the same spinel structure and almost identical lattice parameters (Space group: $P 4_{1} 32, a=0.8352 \mathrm{~nm}$ ) as magnetite. Although it is known that maghemite phase has several characteristic peaks such as (210) and (211) peaks, the intensity of these peaks are only 5\% of highest intensity in the full standard spectrum [38] (JCPDS\# 39-1346). A copper anode is normally employed for routine XRD analysis, but it is difficult to identify the maghemite phases with the $\mathrm{Cu} \mathrm{X}$-ray, because the Fe fluorescence activated by the $\mathrm{Cu} \mathrm{X}$-ray causes a strong fluorescence signal that can smear the characteristic peaks of maghemite. In the present study, a cobalt anode was used to minimize the Fe fluorescence emission as the electron binding energy of $\mathrm{Fe} \mathrm{K} 1 s$ is $7.1 \mathrm{keV}$, which is smaller than the energy of $\mathrm{Cu} \mathrm{K} \alpha \mathrm{X}$-ray $(8.03-8.05 \mathrm{keV})$ but greater than the energy of Co Ka X-ray (6.92-6.93 keV). The XRD data with Co X-ray were of high quality, and even (111) peaks with weak intensity at low $2 \theta$ angle could be clearly observed (Fig. 1). In the standard maghemite pattern, the (111) peak is located at $2 \theta=21.38^{\circ}$, the (210) peak is at $2 \theta=27.68^{\circ}$, and the (211) peak is at $2 \theta=30.41^{\circ}$. In Fig. 1, the characteristic peaks of maghemite, (210) and (211) peaks were not observed, while peak (111) shows up. Moreover, there were no clear doublets at (511) and (440) peaks at high $2 \theta$ angles. Therefore, it was concluded that all these samples exhibit magnetite phases.

Upon close examination of the XRD patterns of the samples doped with Gd, no diffraction peaks from gadolinium hydroxide $\left(2 \theta_{(100)}=18.62^{\circ}, 2 \theta_{(110)}=32.68^{\circ}, 2 \theta_{(101)}=34.11^{\circ}\right.$; JCPDS\# 38-1042), gadolinium oxide $\left(2 \theta_{(222)}=33.30^{\circ}, 2 \theta_{(400)}=38.64^{\circ}, 2 \theta_{(440)}=55.79^{\circ} ; \operatorname{JCPDS} \# 12-797\right)$, gadolinium orthoferrite $\left(\mathrm{GdFeO}_{3}\right.$; 
$2 \theta_{(111)}=30.00^{\circ}, 2 \theta_{(112)}=38.33^{\circ}, 2 \theta_{(200)}=39.07^{\circ} ;$ JCPDS\# 47-67) or gadolinium-iron garnet $\left(\mathrm{Gd}_{3} \mathrm{Fe}_{5} \mathrm{O}_{12}\right.$; $2 \theta_{(400)}=33.43^{\circ}, 2 \theta_{(420)}=37.40^{\circ}, 2 \theta_{(422)}=41.16^{\circ} ;$ JCPDS\# 48-77) were observed. XRD patterns confirmed that the 5 at.\% Gd-doped samples have a pure, single phase magnetite. Furthermore, peaks in all the different magnetite samples have nearly identical $2 \theta$ positions. The $d$ spacing of the (311) peaks with highest intensity were calculated to be $\sim 2.516 \AA$ for all samples. No measurable peak shift could be observed in 5 at.\% Gd-doped samples relative to pure magnetite. This indicates that the Gd-doped samples maintained the inverse cubic spinel structure of magnetite, and Gd did not alter either the crystal structure or the lattice parameter of as-synthesized parent magnetite.

ICP-MS and XPS were performed to determine the elemental composition of the as-synthesized magnetite nanoparticles and verify the presence and form of Gd in the samples (Table 1 and Fig. 2). Elemental analysis by ICP-MS confirmed the presence of Gd in the 5 at.\% Gd-doped magnetite nanoparticles. The percentages of Gd as a fraction of trivalent ions calculated from ICP-MS data were found to be $4.19 \pm 0.43 \%$ and $4.35 \pm 0.08 \%$ for samples with and without Mms6 respectively, which are slightly lower than the initial Gd content $(\sim 5 \%)$ in the precursors (Table 1). For elemental analysis of Gd by XPS, an oxidized gadolinium metal was used as a reference, since the XPS spectra of lanthanide ions are not well studied and different binding energies have been observed, according to the XPS spectra reported [24]. In Fig. 2, Gd3d peaks of 5 at.\% Gd-doped samples exhibited a similar shape and position to that of Gd oxide reference, which also verified the presence of Gd in the samples. The XPS results show that with and without Mms6, the 5 at.\% Gd-doped magnetite nanoparticles have the same binding energy of Gd3d (1187.6 eV), which suggests no discernable effect of Mms6 on the binding energy. The binding energy of Gd3d in doped magnetite is close to that in the $\mathrm{Gd}$ oxide reference $(1187.3 \mathrm{eV})$, indicating that the $\mathrm{Gd}$ ions are in +3 state in the doped samples.

One concern in cation substitution is the distribution of the substituents within the crystals. As reported, Co, $\mathrm{Ni}$ and $\mathrm{Zn}$ are randomly distributed within the magnetite structure, while $\mathrm{Cu}, \mathrm{Mn}$ and $\mathrm{Cd}$ appear to be concentrated near the surface of the crystals [3]. In this study, ion etching removed around a $4 \mathrm{~nm}$ thick layer from the surface. Fig. 3 shows the original XPS peaks of Fe $2 p$ and Gd4d for 5 at.\% Gd-doped magnetite nanoparticles before and after ion etching. The intensity of signals showed little change, including the Gd4d peak. This indicated that Gd ions were within the bulk of the magnetite crystals and not 
just on the surface. Therefore, XRD, ICP-MS and XPS analyses together confirmed that Gd ions are present in the magnetite crystals at the levels that Gd are doped with initially, and it appears that Gd is distributed in the lattice homogeneously. Based on ICP-MS results (Table 2), the composition of 5 at.\% Gd-doped magnetite nanoparticles (with or without Mms6) are $\mathrm{Fe}_{(3-\mathrm{x})} \mathrm{Gd}_{\mathrm{x}} \mathrm{O}_{4}($ where $\mathrm{x}=0.085 \pm 0.002$ ).

$\mathrm{Gd}^{3+}$ has the crystal ionic radius of $1.078 \AA$ for coordination number $(\mathrm{CN})$ of VI, which is much larger than that of the $\mathrm{Fe}^{3+}$ ion (in high-spin state, $0.63 \AA$ for $\mathrm{CN}=\mathrm{IV}$ and $0.785 \AA$ for $\mathrm{CN}=\mathrm{VI}$ ) and that of the $\mathrm{Fe}^{2+}$ ion (in high-spin state, $0.92 \AA$ for $\mathrm{CN}=\mathrm{VI}$ ) $[12,39]$. Here, the substituted trivalent cation percentage is 5 at.\%, which was much higher than the level of lanthanides elements incorporated in magnetite in natural rocks [40]. Thus, 5 at.\% Gd doping may introduce lattice distortion and change of the lattice parameter. XRD patterns showed no measurable peak shift in 5 at.\% Gd-doped magnetite nanoparticles compared with undoped ones. We note that the oxygen framework in magnetite is fairly open and flexible and it can expand or contract without much strain to accommodate ions of larger size than interstitial sites [3]. For instance, all the $\mathrm{Fe}^{2+}$ ions are incorporated in octahedral sites of magnetite, but the ionic radii of $\mathrm{Fe}^{2+}$ ions $(0.92 \AA)$ are greater than the radii of octahedral sites (0.7357-0.8285 $⿱$ A) in magnetite. Moreover, assuming that 10 at. $\% \mathrm{Fe}^{3+}$ are substituted by $\mathrm{Gd}^{3+}$ and all the $\mathrm{Gd}^{3+}$ ions are randomly incorporated in the octahedral sites, the average ionic radii of trivalent ions at octahedral sites are $0.8 r_{\mathrm{Fe} 3+}+0.2 r_{\mathrm{Gd} 3+}=0.8436 \AA$, which is still smaller than the radius of $\mathrm{Fe}^{2+}$ ion $(0.92 \AA)$ at octahedral sites. Thus, a lattice increase corresponding to 10 at.\% Gd substitution for $\mathrm{Fe}^{3+}$ may not lead to a detectable lattice expansion and corresponding peak position shift. More importantly, low crystallinity due to nanoscale size, a common occurrence in the coprecipitation method [1] as evident from XRD and TEM results (see below), also makes it difficult to observe any change in diffraction peak positions. We argue that crystallinity is the dominant effect on measurements of lattice distortion in nanoparticles. Even through 5 at.\% Gd-doped magnetite has a large crystal size (see below) leading to sharp diffraction peaks with high intensity, Gd doping may not increase the crystallinity significantly to show the lattice distortion. Thermal annealing has been reported as a more effective way to improve the crystallinity [41]. Thus, heat treatment was applied in order to show the peak position shift if lattice distortion exists. In addition, the initial Gd percentage was increased to $10 \%$ from the original $5 \%$, and the final doping amount was $8.8 \pm 0.8 \%$, as measured by ICP-MS. The as-synthesized 10 at.\% Gd-doped magnetite nanoparticles were heated to $900^{\circ} \mathrm{C}$ for 4 hours in air and in vacuum (Fig. 4). 
After heating in air, the magnetite phase was oxidized to hematite, mixed with a very small amount of gadolinium iron garnet (Fig. 4a). XRD patterns of 10 at.\% Gd-doped magnetite heated in vacuum (in a sealed glass tube) showed magnetite and/or maghemite, which were difficult to discriminate under the experimental conditions used (Fig. 4b). The position of highest-intensity peak (311) shifted about 0.1 degree to a lower Bragg angle, corresponding to an increase of $0.006 \AA$ in d spacing and $0.02 \AA$ in lattice parameter, which is close to the reported results of Gd-doped Ni-Zn ferrite [42] and Ca-doped magnetite [43] since $\mathrm{Ca}^{2+}$ has a similar ionic radius $(1.14 \AA$ for $\mathrm{CN}=\mathrm{VI})$ [39]. In addition, there were several minor Gd containing phases including gadolinium iron garnet and gadolinium orthoferrite, suggesting that the Gddoped magnetite might be a metastable phase which decomposes to Gd-ferrite, Gd-iron garnet and magnetite at high temperatures [44].

\subsection{Crystal growth through Gd doping:}

In Fig. 1, it is clear that the 5 at.\% Gd-doped magnetite nanoparticles exhibit sharper peaks than the ones without Gd, suggesting that the Gd-doped samples have larger crystal sizes. The well-known Scherrer equation (Eq. 1) was applied to determine the crystal size of magnetite particles [45] without considering the effect of lattice strains.

$D=K \lambda /(\beta \cos \theta)$

The instrumental broadening was determined using the NIST standard reference materials (SRM) 640c silicon powder and corrected for peak broadening due to crystal size. Five diffraction peaks with relatively high intensity (i.e., (220), (311), (400), (511) and (440) peaks) were used to estimate the average crystal size and standard deviation (Table 2). As evident from Table 2, the crystal size of magnetite nanoparticles doubled for samples doped with 5\% Gd, which clearly showed that Gd doping has an effect on the growth of magnetite crystals using an aqueous co-precipitation method.

The as-synthesized magnetite nanoparticles with and without Gd doping were observed under TEM (Fig.5a-d). The particle size was measured and the histograms of size distribution for nanoparticles synthesized at different conditions are shown in Fig. S1. Without $\mathrm{Gd}^{3+}$, the magnetite particles exhibited cuboidal shape and the particle size was $18-20 \mathrm{~nm}$ (Figs. 5a-b, S1, Table 2), which is similar to the values reported previously $[32,33]$. But the effect of Mms6 on the growth of magnetite nanoparticles was 
suppressed. In the presence of $\mathrm{Gd}^{3+}$, the particle size of magnetite particles increased to around 44-46 nm and the size distribution became broader (Figs. 5c-d, S1, Table 2). Magnetite nanoparticles as large as 100$130 \mathrm{~nm}$ could be seen, along with particles of similar shape and size as those without Gd doping (Figs. S1S2). TEM micrographs and histograms confirm that crystal size increased with Gd doping, which was consistent with XRD results presented above, even though due to the low crystallinity of nanoparticles the mean particle size measured using TEM is slightly larger than the crystal size estimated by XRD and the size distribution from TEM results is broader than that calculated using XRD results. The effect of Gd doping or the effect of doping with other lanthanide ions on the crystal size of magnetite synthesized via precipitation method has not been reported before, but Co doping was observed to have a similar effect [21]. The large Gd-doped magnetite nanoparticles did not show well-defined shapes under the TEM (Fig. S2) because there were some fine particles aggregated on the surface of the Gd-doped magnetite nanoparticles due to interparticle interactions (e.g., dipole-dipole, van der Waals electrical double layer) [5, 37].

Using the same method, $\mathrm{GdCl}_{3}$ without iron was added to the base solution to get the pure Gd hydroxide precipitates as a control sample. Fig. 5e shows the morphology of as-prepared Gd hydroxide. It was amorphous and had no defined morphology, which was quite different from the magnetite nanocrystals. Moreover, a physical mixture of magnetite nanoparticles and Gd hydroxide was prepared via this method by adding mixture of $\mathrm{FeCl}_{2}$ and $\mathrm{FeCl}_{3}$ to the base solution followed by precipitation of Gd. In Fig. 5f, very fine magnetite nanocrystals were covered by a thin layer of the amorphous Gd hydroxide. Obviously, crystal growth brought about by Gd doping was related to the initial nucleation stage and/or growth process. Consequently, addition of $\mathrm{Gd}$ ions to the solution of $\mathrm{FeCl}_{2}+\mathrm{FeCl}_{3}$ prior to precipitation resulted in $\mathrm{Gd}$ incorporated to the lattice of the magnetite nanoparticles.

To verify the effect of Gd doping on crystal size, different levels of $\mathrm{Gd}^{3+}(0,2,4,6,8$ and 10 at.\%) were substituted for $\mathrm{Fe}^{3+}$. ICP-MS was used to measure the amount of $\mathrm{Gd}$ in the magnetite nanoparticles and plotted against the average crystal size as shown in Fig. 6. Clearly, the size of the magnetite nanocrystals increased with Gd content, while the size distribution became broader.

Classical crystal formation from solution is described by two stages $[1,12,46]$ : a rapid burst of nucleation followed by a slow growth of the nuclei by diffusion of the solutes [46]. However, magnetite nanoparticles 
synthesized from aqueous solution form via complicated pathways involving phase transformation of several different iron oxyhydroxide species [47]. During nucleation and growth of magnetite nanocrystals from solution, a non-classical crystal nucleation pathway has been reported recently, which does not involve the formation of an intermediate amorphous phase $[48,49]$. Nucleation of magnetite proceeds by rapid agglomeration of primary particles, $1 \sim 2 \mathrm{~nm}$ in size, consisting of a disordered iron (hydr)oxide phase that may arise from interaction of $\mathrm{Fe}^{2+}$ with a $\mathrm{Fe}(\mathrm{OH})_{3}$ hydrogel that is formed locally in the first stage [48, 50]. The nuclei grow by the accretion and fusion of primary particles attaching to their surfaces, which follows classical theory $[48,51]$. In our synthesis procedure, the precursor of mixed $\mathrm{Fe}^{3+}, \mathrm{Gd}^{3+}$ and $\mathrm{Fe}^{2+}$ ions was prepared at a low $\mathrm{pH}(\sim 1.9)$, and then the $\mathrm{pH}$ was rapidly increased to $\sim 12$ with $\mathrm{NaOH}$. At $\mathrm{pH}$ $\sim 1.9$, polynuclear ferric oxide hydrogel, which for simplicity is designated as $\mathrm{Fe}(\mathrm{OH})_{3}$, forms due to the low solubility product of $\mathrm{Fe}(\mathrm{OH})_{3}\left(\mathrm{~K}_{\mathrm{sp}}=10^{-38.8}\right)$ and the relatively high initial concentration of $\mathrm{Fe}(\mathrm{III})$ [3, 52]. We should point out that ion product for ferric and hydroxide ions exceeds the solubility product, $\mathrm{K}_{\mathrm{sp}}$, which is a necessary but not a sufficient condition for the formation of a solid phase, as the solubility product is determined from solubility of bulk crystalline solid, from dissolution of $\mathrm{Fe}(\mathrm{OH})_{3}$ and in low ionic strength solution. Precipitation of solid phase on the other hand, involves supersaturation, and activity coefficients are lower than unity. Nevertheless, various polynuclear species including $\mathrm{Fe}(\mathrm{OH})_{3}(\mathrm{aq})$ are expected to form. Based on the solubility product value, $\sim 98 \%$ of $\mathrm{Fe}(\mathrm{III})$ was consumed to convert to polynuclear species forming a hydrogel, while all of Gd(III) and Fe(II) ions existed in solution as hydrated complexes as the solubility products of $\mathrm{Gd}(\mathrm{OH})_{3}$ and $\mathrm{Fe}(\mathrm{OH})_{2}$ are $10^{-25.7}$ and $10^{-15.1}$ respectively [52]. When precursors were added dropwise to the $\mathrm{NaOH}$ solution $\mathrm{pH} \approx 12, \mathrm{Gd}(\mathrm{OH})_{3}$ hydrogel (Fig. 5e) and $\mathrm{Fe}(\mathrm{OH})_{2}$ solid formed immediately [52]. At this high $\mathrm{pH}$, interaction of $\mathrm{Fe}(\mathrm{OH})_{3}$ hydrogel with free $\mathrm{Fe}^{2+}$ ions resulted in the formation of primary particles, which led to the resorption of $\mathrm{Fe}(\mathrm{OH})_{2}$ and $\mathrm{Gd}(\mathrm{OH})_{3}$ hydrogels. If, on the other hand, the $\mathrm{Gd}(\mathrm{OH})_{3}$ hydrogel was not resorbed, primary magnetite particles would be surrounded by $\mathrm{Gd}(\mathrm{OH})_{3}$ hydrogel (as was observed in the sequential precipitation process) covering the magnetite nanoparticles (Fig. 5f). Although the details of interactions between $\mathrm{Fe}(\mathrm{OH})_{3}$ and $\mathrm{Gd}^{3+}$ were not clearly resolved in the present work, it is clear that the presence of $\mathrm{Gd}^{3+}$ ions leads to enhancement of crystal growth presumably by aggregation and fusion of primary particles. 
Experimental data on the role (or lack thereof) of Mms6 on the crystal size of the Gd-doped crystals is limited to make any conclusive assessments. However, it is safe to assume that within the limits of the experimental conditions employed in this study, Mms6 has no discernable effect on the crystal size. It is possible that the high $\mathrm{pH}$ employed in the precipitation might have caused deterioration of Mms6 or altering its normal configuration rendering it ineffective. In addition, different synthesis conditions employed in the previous work, in which a polymeric gel was used to slow down the diffusion rates of reagents, may have led to differences in crystal growth in the presence of Mms6 [37].

\subsection{Magnetic properties:}

Magnetic hysteresis for updoped and 5 at.\% Gd-doped magnetite was measured at $5 \mathrm{~K}$ and $260 \mathrm{~K}$ as shown in Fig. 7 (with Mms6) and Fig. S3 (without Mms6). No significant differences were observed between the 5 at.\% Gd-doped magnetite synthesized with and without Mms6. The saturation magnetization of magnetite nanoparticles decreased with Gd doping by $\sim 15 \%$ at $5 \mathrm{~K}$ and by $\sim 16 \%$ at $260 \mathrm{~K}$ at $\mathrm{H}=5000 \mathrm{Oe}$ for the samples with Mms6. At $260 \mathrm{~K}$, the undoped sample does not exhibit any hysteresis as shown in low magnetic fields curves, whereas an irreversible $M(H)$ curve is observed for the doped samples (Figs. $7 \mathrm{~b}$, S3b), which was close to properties of magnetite doped with other lanthanide ions reported previously [24]. However, only a slight difference in the coercivity and remnant magnetization at $5 \mathrm{~K}$ were observed with Gd doping. Compared with the 5 at.\% Gd-doped magnetite sample, magnetite mixed with $5 \% \mathrm{Gd}(\mathrm{OH})_{3}$ (Fig. 5f) exhibited higher saturation magnetization and zero coercivity (Fig. S4), similar to that observed with undoped magnetite. The small but distinct differences between doped and physically mixed samples indicate the change of magnetic behaviors from superparamagnetism to ferrimagnetism, which resulted from the effect of Gd doping and simultaneous increase in size.

As mentioned before, the particle size of magnetite affects its magnetic properties. In theory, the coercivity, $\mathrm{H}_{c}$, of undoped magnetite nanoparticles is zero when the size is below the superparamagnetic threshold size $\left(d<d_{s}\right)$, and increases slowly from zero as a function of particle size $d\left(H_{c} \propto\left(1-\left(d_{s} / d\right)^{1.5}\right)\right)$ in the singledomain region $\left(\mathrm{d}_{\mathrm{s}}<\mathrm{d}<\mathrm{d}_{0}\right)$ [53]. Meanwhile, Gd doping may also increase $\mathrm{H}_{\mathrm{c}}$ as it can introduce magnetic anisotropy [24]. Size-dependence of saturation magnetization, $M_{s}$, has also been reported $[15,54]$ and $M_{s}$ 
increases gradually through superparamagnetic region and single domain region, but Gd substitution decreases $\mathrm{M}_{\mathrm{s}}$ in the spinel structure [42, 55-57]. Here, we observed the increased $\mathrm{H}_{\mathrm{c}}$ (from 0 to $\sim 65 \mathrm{Oe}$ ) and decreased magnetization at $\mathrm{H}=5000 \mathrm{Oe}$, where the measured magnetization was almost totally saturated. Clearly, Gd doping and simultaneous increase in size contributed together to result in the increase of $\mathrm{H}_{\mathrm{c}}$, while the effect of Gd doping on $\mathrm{M}_{\mathrm{s}}$ is the dominant one compared to the size effect. The decrease of $\mathrm{M}_{\mathrm{s}}$ might be attributed to the site preference of Gd ions, probably octahedral sites in magnetite $[19,58]$; variations in the compositions concomitant with $\mathrm{Fe}-\mathrm{Gd}$ interactions which are different from $\mathrm{Fe}-\mathrm{Fe}$ interactions; as well as change of the surface effect resulting from the unpaired surface spins on the magnetic nanoparticles [42, 57], and require further study.

\section{Conclusions}

Using an aqueous co-precipitation method under mild conditions, Gd doping has been demonstrated to influence the crystal growth and magnetic properties of magnetite nanoparticles. 5 at.\% Gd-doped magnetite nanoparticles of pure phase have been successfully synthesized and experimental evidence from XRD, ICP-MS and XPS points to the random incorporation of Gd ions in the magnetite lattice. The chemical composition of 5 at.\% Gd-doped magnetite was $\mathrm{Fe}_{(3-\mathrm{x})} \mathrm{Gd}_{\mathrm{x}} \mathrm{O}_{4}(\mathrm{x}=0.085 \pm 0.002)$ determined by ICP-MS. Gd doping plays an important role in the crystal growth process, and was shown to make magnetite nanoparticles grow larger. Typically the crystal size of 5 at.\% Gd-doped magnetite nanoparticles increased about two-fold, which was confirmed by XRD and TEM. However, the effect of the bacterial biomineralization protein Mms6 on the growth of magnetite particles was not prominent in this synthesis method. Gd doping with simultaneous crystal growth leads to clear differences in magnetic properties. The 5 at.\% Gd-doped magnetite nanoparticles showed ferrimagnetic properties with small coercivity at $260 \mathrm{~K}$ in contrast to the undoped, superparamagnetic magnetite nanoparticles. 


\section{Acknowledgements}

Thanks to Prof. Marit Nilsen-Hamilton's group from Iowa State University for providing the Mms6 protein and for useful discussions. We also thank Ms. Jonna Berry from Ames Laboratory for conducting ICP-MS measurements. Research was supported by the U.S. Department of Energy, Office of Basic Energy Sciences. The Ames Laboratory is operated for the U.S. Department of Energy by Iowa State University under Contract No. DE-AC02-07CH11358.

\section{References}

[1] S. Laurent, D. Forge, M. Port, A. Roch, C. Robic, L. Vander Elst, R.N. Muller, Magnetic Iron Oxide Nanoparticles: Synthesis, Stabilization, Vectorization, Physicochemical Characterizations, and Biological Applications, Chem. Rev., 108 (2008) 2064-2110.

[2] A.-H. Lu, E.L. Salabas, F. Schüth, Magnetic Nanoparticles: Synthesis, Protection, Functionalization, and Application, Angew. Chem., Int. Ed., 46 (2007) 1222-1244.

[3] R.M. Cornell, U. Schwertmann, The iron oxides: structure, properties, reactions, occurrences and uses, John Wiley \& Sons, 2003.

[4] A.K. Gupta, M. Gupta, Synthesis and surface engineering of iron oxide nanoparticles for biomedical applications, Biomaterials, 26 (2005) 3995-4021.

[5] T. Prozorov, D.A. Bazylinski, S.K. Mallapragada, R. Prozorov, Novel magnetic nanomaterials inspired by magnetotactic bacteria: Topical review, Mater. Sci. Eng., R, 74 (2013) 133-172.

[6] Q.A. Pankhurst, J. Connolly, S.K. Jones, J. Dobson, Applications of magnetic nanoparticles in biomedicine, J. Phys. D: Appl. Phys., 36 (2003) R167.

[7] D.J. Dunlop, Superparamagnetic and single-domain threshold sizes in magnetite, J. Geophys. Res., 78 (1973) 1780-1793.

[8] R.F. Butler, S.K. Banerjee, Theoretical single-domain grain size range in magnetite and titanomagnetite, J. Geophys. Res., 80 (1975) 4049-4058.

[9] K.M. Krishnan, A.B. Pakhomov, Y. Bao, P. Blomqvist, Y. Chun, M. Gonzales, K. Griffin, X. Ji, B.K.

Roberts, Nanomagnetism and spin electronics: materials, microstructure and novel properties, J. Mater. Sci., 41 (2006) 793-815.

[10] C. Xu, S. Sun, Superparamagnetic nanoparticles as targeted probes for diagnostic and therapeutic applications, Dalton Trans., (2009) 5583-5591.

[11] P. Majewski, B. Thierry, Functionalized magnetite nanoparticles - synthesis, properties, and bioapplications, Crit. Rev. Solid State Mater. Sci., 32 (2007) 203-215.

[12] U. Schwertmann, R.M. Cornell, Iron Oxides in the Laboratory: Preparation and Characterization, Wiley, 2000.

[13] S. Sun, H. Zeng, Size-Controlled Synthesis of Magnetite Nanoparticles, J. Am. Chem. Soc., 124 (2002) 8204-8205.

[14] N.R. Jana, Y. Chen, X. Peng, Size- and Shape-Controlled Magnetic (Cr, Mn, Fe, Co, Ni) Oxide Nanocrystals via a Simple and General Approach, Chem. Mater., 16 (2004) 3931-3935.

[15] J. Santoyo Salazar, L. Perez, O. de Abril, L. Truong Phuoc, D. Ihiawakrim, M. Vazquez, J.-M. Greneche, S. Begin-Colin, G. Pourroy, Magnetic Iron Oxide Nanoparticles in 10-40 nm Range: Composition in Terms of Magnetite/Maghemite Ratio and Effect on the Magnetic Properties, Chem. Mater., 23 (2011) 1379-1386.

[16] D. Kim, N. Lee, M. Park, B.H. Kim, K. An, T. Hyeon, Synthesis of Uniform Ferrimagnetic Magnetite Nanocubes, J. Am. Chem. Soc., 131 (2009) 454-455. 
[17] Nyir, I. Kósa, D. Csákberé Nyinagy, M. Pósfai, Size and shape control of precipitated magnetite nanoparticles, Eur. J. Mineral., 21 (2009) 293-302.

[18] J. Baumgartner, L. Bertinetti, M. Widdrat, A.M. Hirt, D. Faivre, Formation of Magnetite Nanoparticles at Low Temperature: From Superparamagnetic to Stable Single Domain Particles, PLoS ONE, 8 (2013) e57070.

[19] R.C. O'Handley, Modern Magnetic Materials: Principles and Applications, Wiley, 1999.

[20] S. Staniland, W. Williams, N. Telling, L. Van Der, A. Harrison, B. Ward, Controlled cobalt doping of magnetosomes in vivo, Nat. Nanotechnol., 3 (2008) 158-162.

[21] J.M. Galloway, A. Arakaki, F. Masuda, T. Tanaka, T. Matsunaga, S.S. Staniland, Magnetic bacterial protein Mms6 controls morphology, crystallinity and magnetism of cobalt-doped magnetite nanoparticles in vitro, J. Mater. Chem., 21 (2011) 15244-15254.

[22] F. Wang, Y. Han, C.S. Lim, Y. Lu, J. Wang, J. Xu, H. Chen, C. Zhang, M. Hong, X. Liu, Simultaneous phase and size control of upconversion nanocrystals through lanthanide doping, Nature, 463 (2010) 1061-1065.

[23] D. Chen, Y. Wang, Impurity doping: a novel strategy for controllable synthesis of functional lanthanide nanomaterials, Nanoscale, 5 (2013) 4621-4637.

[24] C.R. De Silva, S. Smith, I. Shim, J. Pyun, T. Gutu, J. Jiao, Z. Zheng, Lanthanide(III)-Doped Magnetite Nanoparticles, J. Am. Chem. Soc., 131 (2009) 6336-6337.

[25] X. Liang, X. Wang, J. Zhuang, Y. Chen, D. Wang, Y. Li, Synthesis of Nearly Monodisperse Iron Oxide and Oxyhydroxide Nanocrystals, Adv. Funct. Mater., 16 (2006) 1805-1813.

[26] G. Wang, Q. Peng, Y. Li, Lanthanide-Doped Nanocrystals: Synthesis, Optical-Magnetic Properties, and Applications, Acc. Chem. Res., 44 (2011) 322-332.

[27] P. Drake, H.-J. Cho, P.-S. Shih, C.-H. Kao, K.-F. Lee, C.-H. Kuo, X.-Z. Lin, Y.-J. Lin, Gd-doped ironoxide nanoparticles for tumour therapy via magnetic field hyperthermia, J. Mater. Chem., 17 (2007) 49144918.

[28] G. Liu, X. Chen, Chapter 233 Spectroscopic properties of lanthanides in nanomaterials, in: J.-C.B.

Karl A. Gschneidner, K.P. Vitalij (Eds.) Handbook on the Physics and Chemistry of Rare Earths, Elsevier, 2007, pp. 99-169.

[29] N. Sakai, L. Zhu, A. Kurokawa, H. Takeuchi, S. Yano, T. Yanoh, N. Wada, S. Taira, Y. Hosokai, A. Usui, Synthesis of Gd2O3 nanoparticles for MRI contrast agents, in: J Phys Conf Ser., IOP Publishing, 2012, pp. 012008.

[30] Z. Zhou, D. Huang, J. Bao, Q. Chen, G. Liu, Z. Chen, X. Chen, J. Gao, A Synergistically Enhanced T1-T2 Dual-Modal Contrast Agent, Adv. Mater., 24 (2012) 6223-6228.

[31] K.H. Bae, Y.B. Kim, Y. Lee, J. Hwang, H. Park, T.G. Park, Bioinspired Synthesis and

Characterization of Gadolinium-Labeled Magnetite Nanoparticles for Dual Contrast T1- and T2-Weighted Magnetic Resonance Imaging, Bioconjugate Chem., 21 (2010) 505-512.

[32] A. Arakaki, J. Webb, T. Matsunaga, A novel protein tightly bound to bacterial magnetic particles in Magnetospirillum magneticum strain AMB-1, J. Biol. Chem., 278 (2003) 8745-8750.

[33] L. Wang, T. Prozorov, P.E. Palo, X. Liu, D. Vaknin, R. Prozorov, S. Mallapragada, M. Nilsen-

Hamilton, Self-Assembly and Biphasic Iron-Binding Characteristics of Mms6, A Bacterial Protein That Promotes the Formation of Superparamagnetic Magnetite Nanoparticles of Uniform Size and Shape, Biomacromolecules, 13 (2012) 98-105.

[34] W. Wang, W. Bu, L. Wang, P.E. Palo, S. Mallapragada, M. Nilsen-Hamilton, D. Vaknin, Interfacial Properties and Iron Binding to Bacterial Proteins That Promote the Growth of Magnetite Nanocrystals: Xray Reflectivity and Surface Spectroscopy Studies, Langmuir, 28 (2012) 4274-4282.

[35] S. Feng, L. Wang, P. Palo, X. Liu, S. Mallapragada, M. Nilsen-Hamilton, Integrated self-assembly of the mms6 magnetosome protein to form an iron-responsive structure, Int. J. Mol. Sci., 14 (2013) 1459414606.

[36] H. Zhang, X. Liu, S. Feng, W. Wang, K. Schmidt-Rohr, M. Akinc, M. Nilsen-Hamilton, D. Vaknin, S. Mallapragada, Morphological Transformations in the Magnetite Biomineralizing Protein Mms6 in Iron Solutions: A Small-Angle X-ray Scattering Study, Langmuir, 31 (2015) 2818-2825.

[37] T. Prozorov, S.K. Mallapragada, B. Narasimhan, L. Wang, P. Palo, M. Nilsen-Hamilton, T.J. Williams, D.A. Bazylinski, R. Prozorov, P.C. Canfield, Protein-Mediated Synthesis of Uniform Superparamagnetic Magnetite Nanocrystals, Adv. Funct. Mater., 17 (2007) 951-957. 
[38] W. Kim, C.-Y. Suh, S.-W. Cho, K.-M. Roh, H. Kwon, K. Song, I.-J. Shon, A new method for the identification and quantification of magnetite-maghemite mixture using conventional X-ray diffraction technique, Talanta, 94 (2012) 348-352.

[39] R. Shannon, Revised effective ionic radii and systematic studies of interatomic distances in halides and chalcogenides, Acta Crystallogr. Sect. A, 32 (1976) 751-767.

[40] H.H. Schock, Distribution of rare-earth and other trace elements in magnetites, Chem. Geol., 26 (1979) 119-133.

[41] K.J. Chen, T.H. Fang, F.Y. Hung, L.W. Ji, S.J. Chang, S.J. Young, Y.J. Hsiao, The crystallization and physical properties of Al-doped ZnO nanoparticles, Appl. Surf. Sci., 254 (2008) 5791-5795.

[42] A. Mahesh Kumar, M. Chaitanya Varma, G.S.V.R.K. Choudary, P. Prameela, K.H. Rao, Influence of gadolinium on magnetization and DC resistivity of Ni-Zn nanoferrites, J. Magn. Magn. Mater, 324 (2012) 68-71.

[43] J. de Sitter, A. Govaert, E. de Grave, D. Chambaere, G. Robbrecht, A mössbauer study of Ca2+containing magnetites, Phys. Status Solidi A, 43 (1977) 619-624.

[44] V. Buscaglia, M.T. Buscaglia, L. Giordano, A. Martinelli, M. Viviani, C. Bottino, Growth of ternary oxides in the Gd2O3-Fe2O3 system. A diffusion couple study, Solid State Ion., 146 (2002) 257-271.

[45] J.I. Langford, A.J.C. Wilson, Scherrer after sixty years: A survey and some new results in the determination of crystallite size, J. Appl. Crystallogr., 11 (1978) 102-113.

[46] J.W. Mullin, Crystallization, Elsevier Science, 2001.

[47] T. Ahn, J.H. Kim, H.-M. Yang, J.W. Lee, J.-D. Kim, Formation Pathways of Magnetite Nanoparticles by Coprecipitation Method, J. Phys. Chem. C, 116 (2012) 6069-6076.

[48] J. Baumgartner, A. Dey, P.H.H. Bomans, C. Le Coadou, P. Fratzl, N.A.J.M. Sommerdijk, D. Faivre, Nucleation and growth of magnetite from solution, Nat. Mater., 12 (2013) 310-314.

[49] J. De Yoreo, Crystal nucleation: More than one pathway, Nat. Mater., 12 (2013) 284-285.

[50] J.P. Jolivet, P. Belleville, E. Tronc, J. Livage, Influence of Fe(II) on the formation of the spinel iron oxide in alkaline medium, Clays Clay Miner., 40 (1992) 531-539.

[51] P. Fratzl, J.L. Lebowitz, O. Penrose, J. Amar, Scaling functions, self-similarity, and the morphology of phase-separating systems, Phys. Rev. B, 44 (1991) 4794-4811.

[52] A.E. Martell, R.M. Smith, Critical stability constants. 4. Inorganic complexes, Plenum Press, 1976.

[53] D.J. Dunlop, Ö. Özdemir, Rock Magnetism: Fundamentals and Frontiers, Cambridge University Press, 1997.

[54] Z. Li, Q. Sun, M. Gao, Preparation of Water-Soluble Magnetite Nanocrystals from Hydrated Ferric Salts in 2-Pyrrolidone: Mechanism Leading to Fe3O4, Angew. Chem., Int. Ed., 44 (2005) 123-126.

[55] J. Peng, M. Hojamberdiev, Y. Xu, B. Cao, J. Wang, H. Wu, Hydrothermal synthesis and magnetic properties of gadolinium-doped CoFe2O4 nanoparticles, J. Magn. Magn. Mater, 323 (2011) 133-137.

[56] R.N. Panda, J.C. Shih, T.S. Chin, Magnetic properties of nano-crystalline Gd- or Pr-substituted $\mathrm{CoFe} 2 \mathrm{O} 4$ synthesized by the citrate precursor technique, J. Magn. Magn. Mater, 257 (2003) 79-86.

[57] B. Issa, I. Obaidat, B. Albiss, Y. Haik, Magnetic Nanoparticles: Surface Effects and Properties Related to Biomedicine Applications, Int. J. Mol. Sci., 14 (2013) 21266-21305.

[58] A. Navrotsky, O.J. Kleppa, The thermodynamics of cation distributions in simple spinels, J. Inorg.

Nucl. Chem., 29 (1967) 2701-2714. 


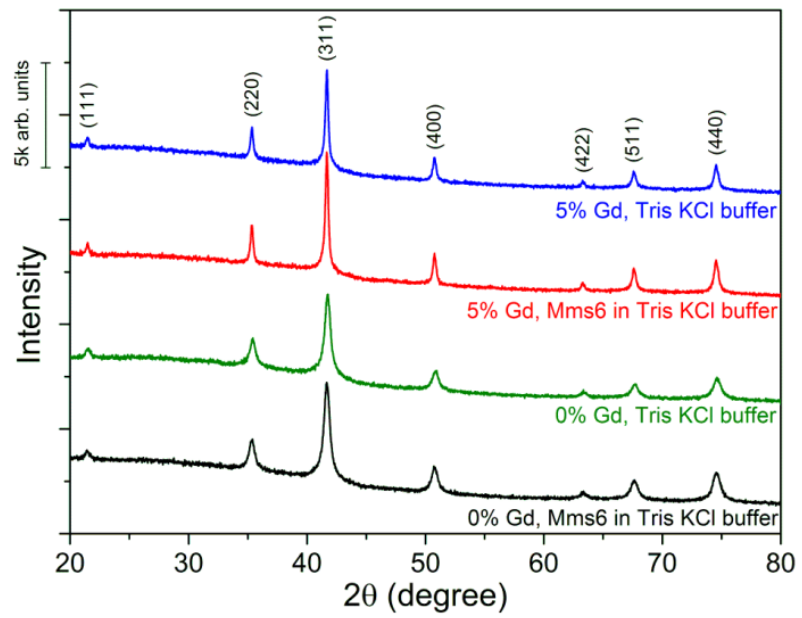

Fig. 1. X-ray powder diffraction patterns of magnetite nanoparticles prepared with and without 5 at.\% Gd doping in the presence and absence of Mms6 protein. The patterns clearly show that the as-prepared materials exhibit magnetite structure with no discernible impurity phases. 

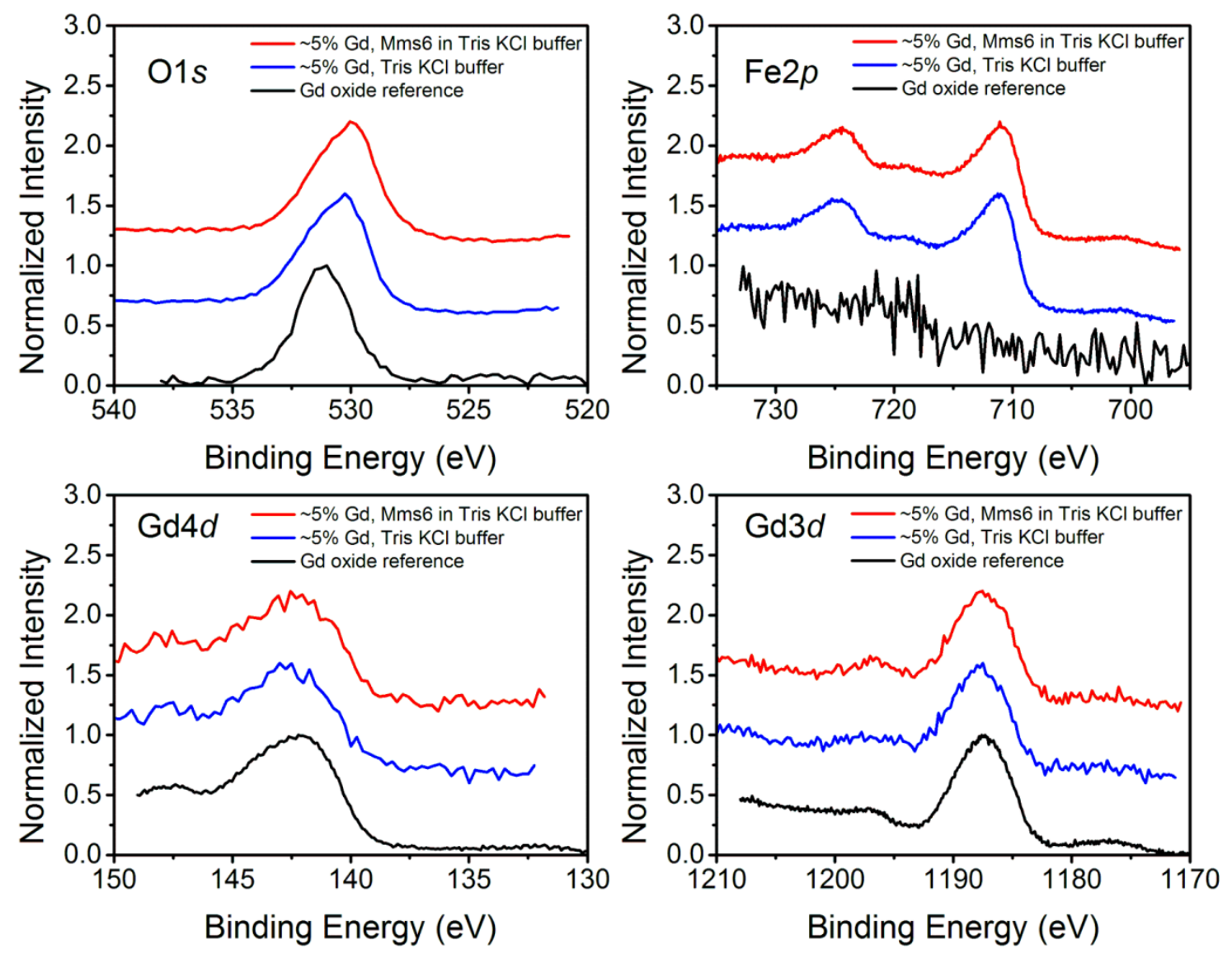

Fig. 2. XPS spectra of $\mathrm{O} 1 s, \mathrm{Fe} 2 p, \mathrm{Gd} 4 d$ and $\mathrm{Gd} 3 d$ for 5 at.\% Gd-doped magnetite nanoparticles prepared in the absence of Mms6 (blue) and in the presence of Mms6 (red), and the Gd oxide on the Gd metal as a reference (black). The binding energy was calibrated with $\mathrm{C} 1 s\left(\mathrm{E}_{\mathrm{b}}=284.8 \mathrm{eV}\right)$. 

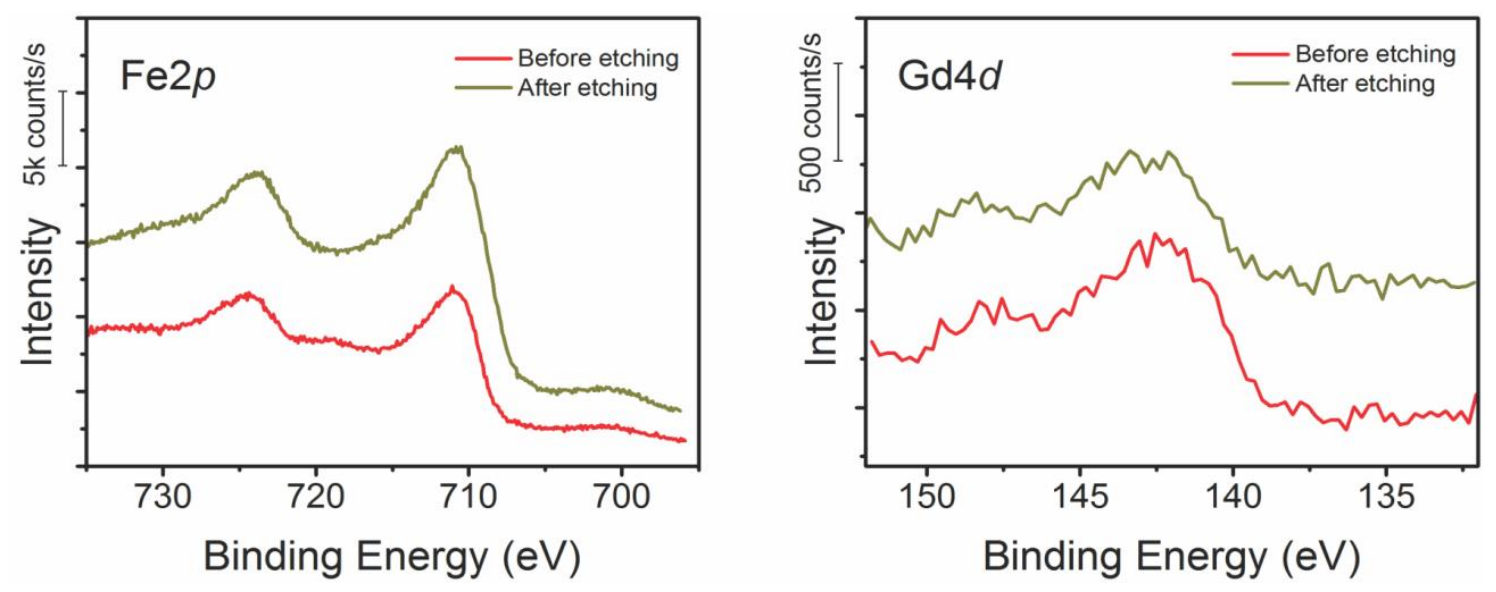

Fig. 3. XPS spectra of $\mathrm{Fe} 2 p$ and $\mathrm{Gd} 4 d$ for Gd-doped magnetite nanoparticles prepared in the presence of Mms6 before etching (red) and after etching (olive green) with calibration via $\mathrm{C} 1 s\left(\mathrm{E}_{\mathrm{b}}=284.8 \mathrm{eV}\right)$. 
(a)

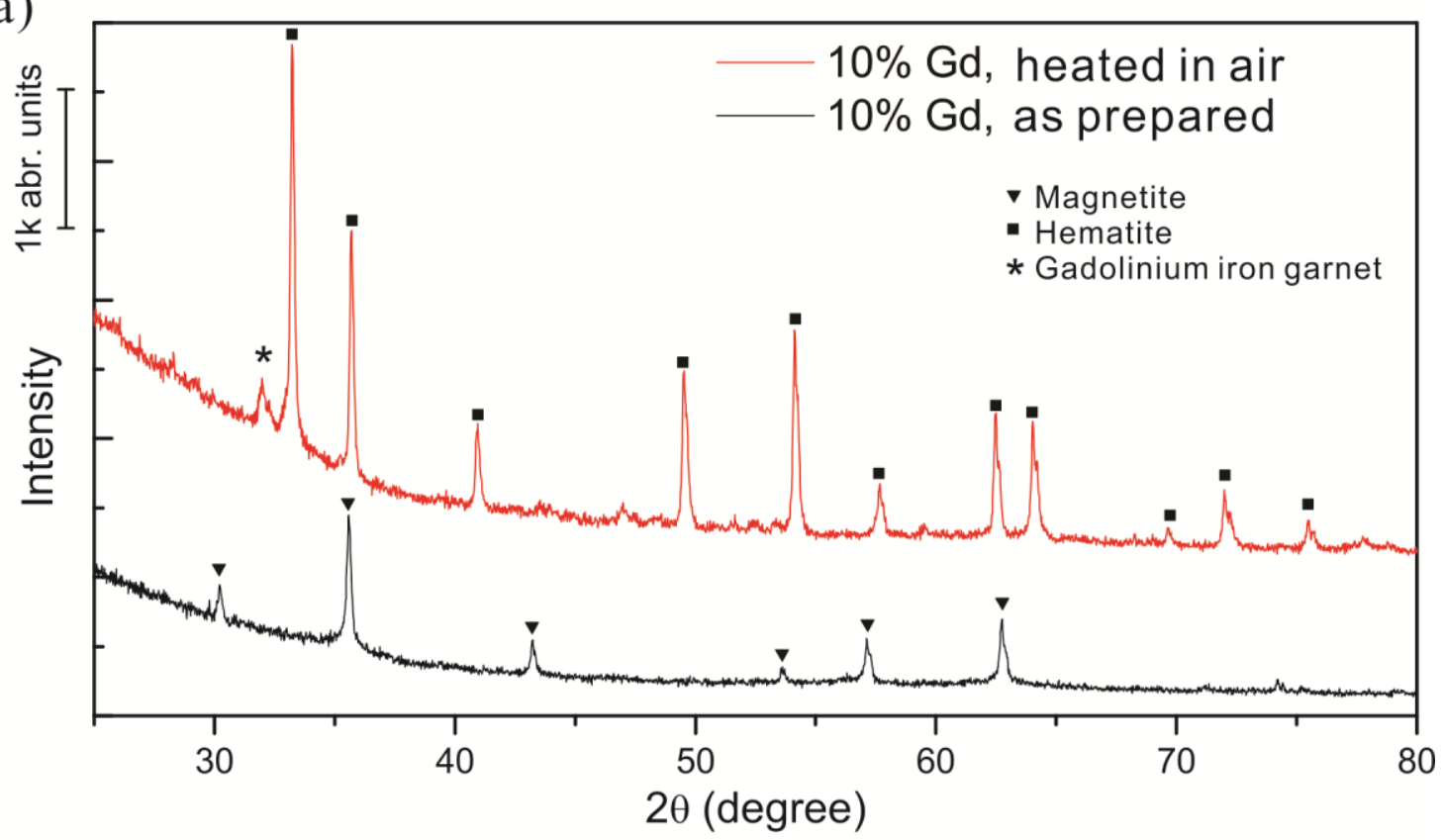

(b)

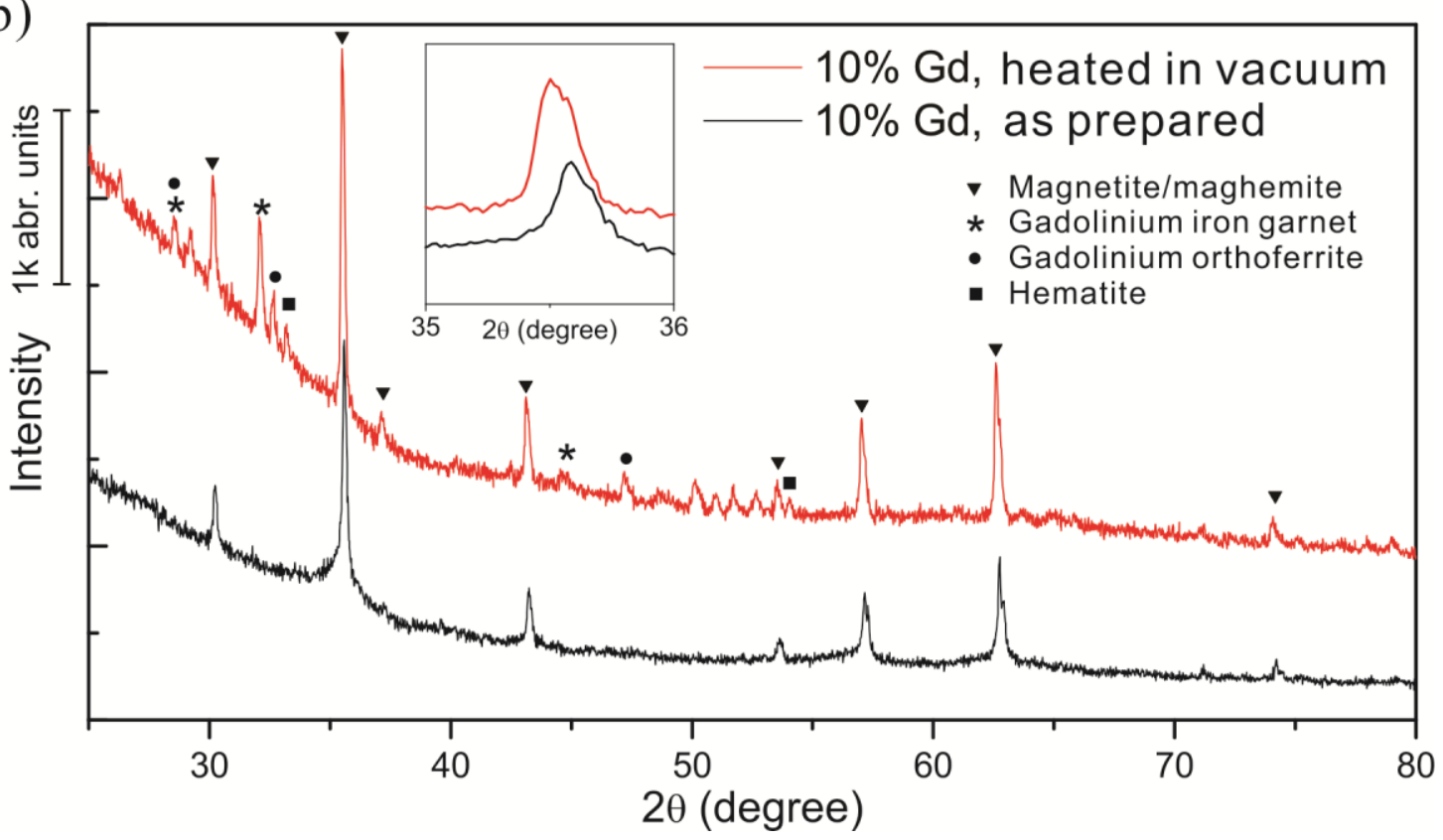

Fig. 4. X-ray powder diffraction patterns of as-prepared 10 at.\% Gd-doped magnetite samples before and after heat treatment (a) in air and (b) in vacuum (Inset: peak 311). A copper Ka radiation source with a wavelength of $0.154187 \mathrm{~nm}$ was employed. 

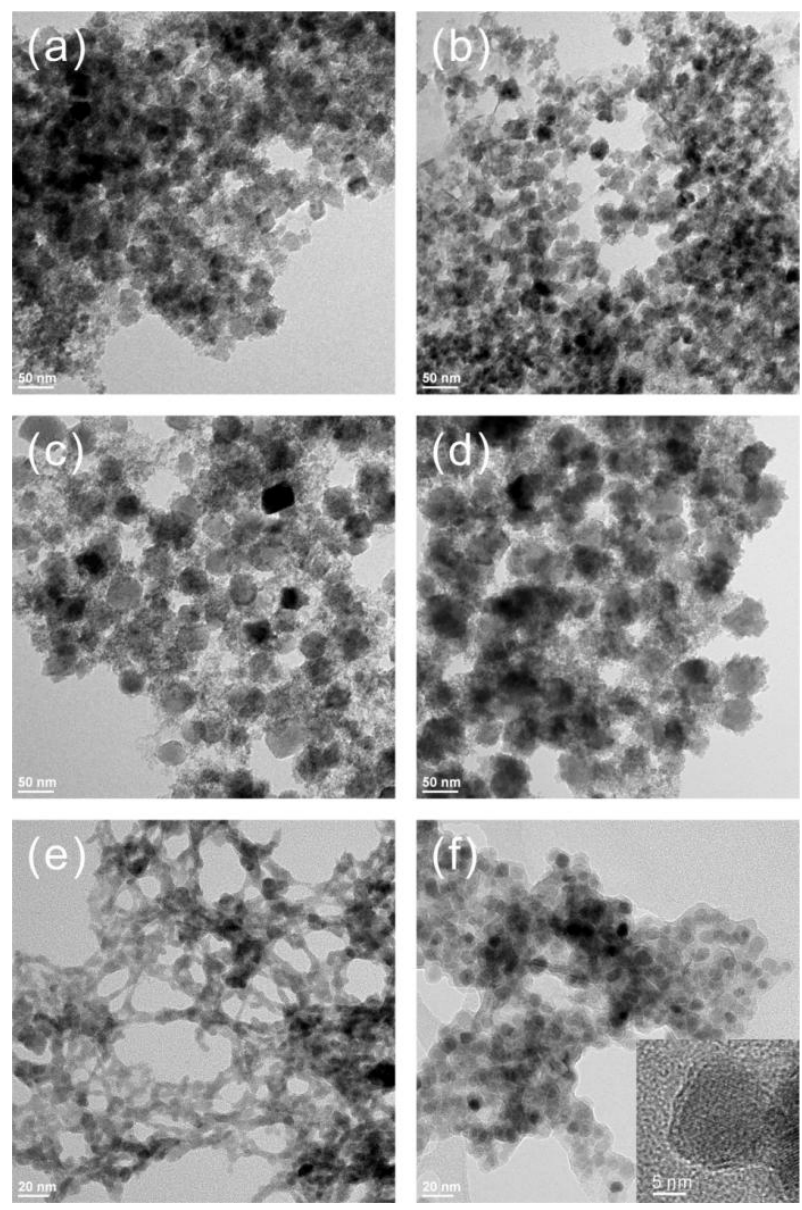

Fig 5. TEM images of nanoparticles synthesized via co-precipitation method: (a) updoped magnetite in the absence of Mms6, (b) updoped magnetite in the presence of Mms6, (c) 5 at.\% Gd-doped magnetite in the absence of Mms6, and (d) 5 at.\% Gd-doped magnetite in the presence of Mms6, (e) Gd hydroxide synthesized by precipitation of $\mathrm{GdCl}_{3}$ in $\mathrm{NaOH}$, and (f) magnetite nanoparticles covered with gelatinous $\mathrm{Gd}$ hydroxide layer (Inset: HRTEM image) prepared by adding mixture of $\mathrm{FeCl}_{2}$ and $\mathrm{FeCl}_{3}$ to the $\mathrm{NaOH}$ solution followed by precipitation of $\mathrm{GdCl}_{3}$. 


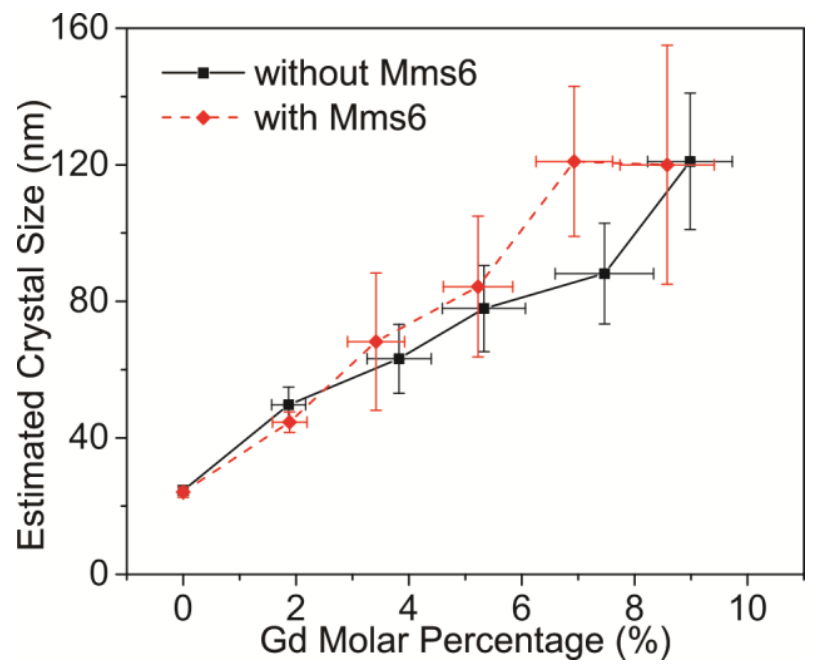

Fig. 6. Crystal size of magnetite nanoparticles synthesized with different amounts of Gd. Gd molar percentages as fraction of trivalent ions were measured by ICP-MS, while the crystal size was calculated using Scherrer equation from XRD data. 

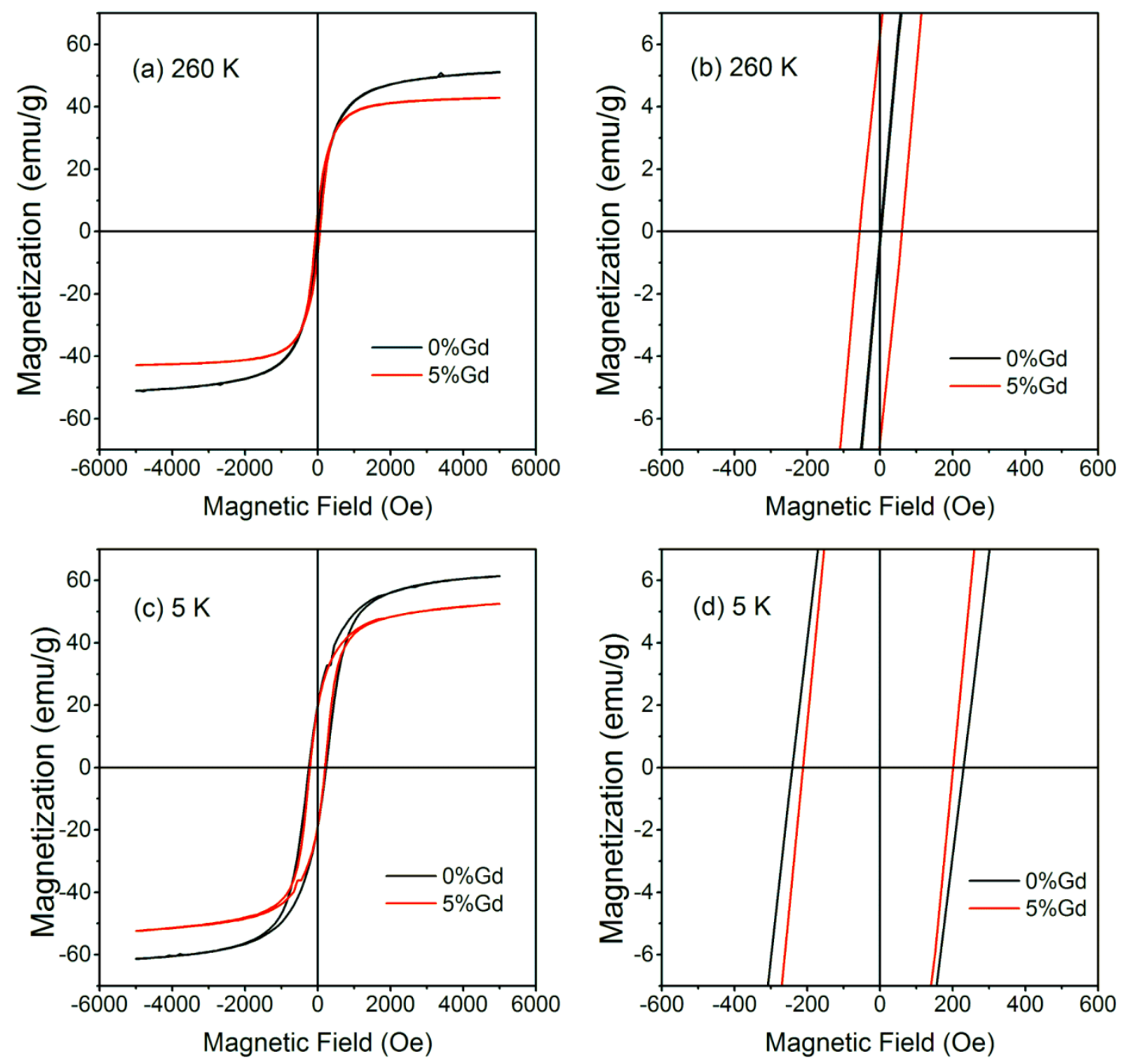

Fig. 7. Magnetization (M) vs. magnetic field $(\mathrm{H})$ curves for magnetite nanoparticles synthesized in the presence of Mms6, without Gd doping (black) and with 5 at.\% Gd doping (red): (a) at 260K, and (b) corresponding low field curves at $260 \mathrm{~K}$; (c) at $5 \mathrm{~K}$, and (d) corresponding low field curves at $5 \mathrm{~K}$. 
Table 1. The elemental analysis of as-synthesized 5 at.\% Gd-doped magnetite nanoparticles by ICP-MS.

Gd molar doping percentage as fraction of trivalent ions is expressed as $\left[\mathrm{Gd}^{3+}\right] /\left(\left[\mathrm{Fe}^{3+}\right]+\left[\mathrm{Gd}^{3+}\right]\right) \times 100 \%$.

It was assumed that $\left[\mathrm{Fe}^{2+}\right] /\left(\left[\mathrm{Fe}^{3+}\right]+\left[\mathrm{Gd}^{3+}\right]\right)=0.5$ in the Gd-doped magnetite samples.

\begin{tabular}{ccc}
\hline $\begin{array}{c}\text { Gd-doped } \\
\text { magnetite } \\
\text { nanoparticles }\end{array}$ & $\sim 5 \% \mathrm{Gd}$ & $\sim 5 \% \mathrm{Gd}$ \\
\cline { 2 - 3 } & with Mms6 & without Mms6 \\
\hline $\begin{array}{c}\text { Measured } \\
\mathrm{Gd}, \% \text { of Fe }\end{array}$ & $4.19 \pm 0.43$ & $4.35 \pm 0.08$ \\
$\mathrm{Gd}: \mathrm{Fe}$ & & \\
atomic ratio & $0.0287 \pm 0.0030$ & $0.0298 \pm 0.0005$ \\
$\mathrm{x}$ in & & \\
$\mathrm{Fe}_{(3-\mathrm{x})} \mathrm{Gd}_{\mathrm{x}} \mathrm{O}_{4}$ & $0.084 \pm 0.009$ & $0.087 \pm 0.002$ \\
\hline
\end{tabular}

Table 2. The size of updoped and 5 at.\% Gd-doped magnetite nanoparticles characterized by XRD and TEM.

\begin{tabular}{ccccc}
\hline \multirow{2}{*}{$\begin{array}{c}\text { Magnetite synthesized in } \\
\text { different conditions }\end{array}$} & with Mms6 & $\begin{array}{c}\text { without } \\
\text { Mms6 }\end{array}$ & with Mms6 & $\begin{array}{c}\text { without } \\
\text { Mms6 }\end{array}$ \\
\cline { 2 - 5 } & $17 \pm 2$ & $16 \pm 2$ & $44 \pm 7$ & $42 \pm 4$ \\
$\begin{array}{c}\text { Crystal size estimated by } \\
\text { XRD (nm) }\end{array}$ & $20 \pm 6$ & $18 \pm 6$ & $46 \pm 13$ & $44 \pm 12$ \\
$\begin{array}{c}\text { Particle size measured in } \\
\text { TEM (nm) }\end{array}$ & & & \\
\hline
\end{tabular}




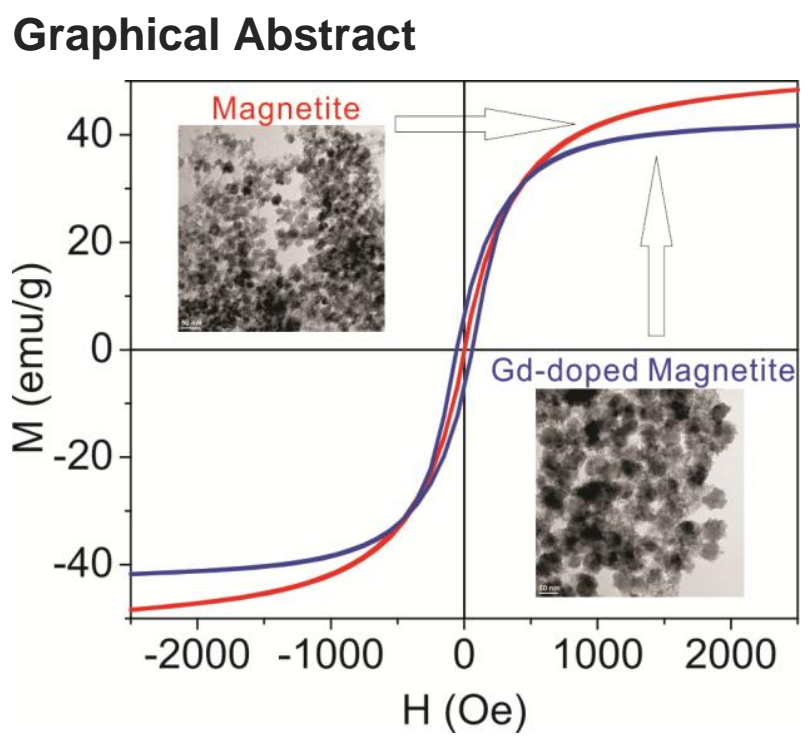

